\title{
Agricultural air quality in Europe and the future perspectives
}

\author{
J.W. Erisman \\ A. Bleeker \\ A. Hensen \\ A.T. Vermeulen \\ Published in Atmospheric Environment 42 (2008) 3209-3217
}




\title{
Agricultural air quality in Europe and the future perspectives
}

\author{
Jan Willem Erisman*, Albert Bleeker, Arjan Hensen, Alex Vermeulen \\ Energy Research Center of the Netherlands, Petten, NH, 1755 ZG, The Netherlands
}

Received 24 September 2006; received in revised form 3 April 2007; accepted 4 April 2007

\begin{abstract}
Agricultural emissions in Europe are important to several atmospheric transport-related environmental issues. These include local and regional air quality problems, such as PM exposure, eutrophication and acidification, toxics and contribution to greenhouse gas emissions, resulting in a number of environmental impacts. Over Europe, agricultural emissions are variable in space and time and the contribution to the different issues are variable. Most important are ammonia (90\%), PM (20\%) and methane and nitrous oxide (both 5\%). Policies have been developed to combat some of the emissions with success in some countries. However, future, national and European policies are necessary to successfully decrease emissions and its related problems. Current research issues include the quantification of non-point sources, the atmosphere-biosphere exchange of ammonia, the quantification of landscape processes and the primary and secondary emissions of PM.
\end{abstract}

(C) 2007 Elsevier Ltd. All rights reserved.

Keywords: Air quality; Agriculture; Europe; Emission; Greenhouse gas; Nitrogen; Ammonia; Particulate matter

\section{Introduction}

European agriculture is extremely diverse, ranging from large, highly intensive and specialized commercial holdings to subsistence farming using mainly traditional practices. Consequently, impacts on the environment vary in scale and intensity and may be positive or negative. There is a legacy of significant environmental damage associated with agriculture in Europe, the Caucasus and central Asia, often associated with unique ecosystems, where exploitation of resources (such as freshwater for irrigation) was excessive. The dramatic decline in resource use in these countries, largely due to

\footnotetext{
*Corresponding author. Tel.: + 31224564155.

E-mail address: erisman@ecn.nl (J.W. Erisman).
}

economic restructuring rather than policy, consumer or technological developments, has scaled back many environmental pressures.

A common policy objective throughout Europe for several decades was to increase food production. Farmers increased agricultural output significantly between the 1940s and 1990s in response to such policies. Supported by public investment, this resulted in mechanization combined with the abandonment of traditional practices, reliance on non-renewable inputs such as inorganic fertilizers and pesticides, the cultivation of marginal land and improvements in production efficiency. In Europe, the common agricultural policy (CAP) and several national policies encouraged intensification. This took various forms, including the sustained use of chemical inputs, increasing field size and higher 
stocking densities. Intensified farm management led to discontinuation of traditional fallowing practices and crop rotations resulting in a displacement of leguminous fodder crops with increased use of silage and maize. Specialization and intensification have resulted in a decrease in the number of farm holdings and numbers employed, as well as a rationalization of production leading to less diversity of local agricultural habitats.

Agriculture is an important sector contributing to environmental effects and more specifically air quality-related issues. Air quality contributes to human health through exposure of ammonia, toxic organic compounds, pesticides and particulates. Air quality also contributes to climate change in the form of greenhouse gases and as cooling aerosols. After deposition eutrophication and acidification might occur endangering biodiversity, and affecting the net-greenhouse gas exchange between the atmosphere and biosphere. There are two ways to assess the contribution of agriculture to air quality, that is the share of agricultural emissions to the total emissions in Europe, or through the contribution of agriculture to the observed effects in Europe. The latter is less uncertain and not followed here. The focus of this paper is on Europe and first addresses the changes in emissions, followed by the current issues in research and ending with future perspectives.

\section{Changes in drivers relevant for agricultural emissions over time}

Fig. 1 shows some primary drivers that are relevant for agricultural emissions in Europe. It shows that GDP increased gradually between 1960 and 2002. Agricultural area did not change much and a steady increase in fertilizer use was necessary to increase the food production. After the opening of the East European countries at the end of the 1980 s, the fertilizer consumption decreased by $40 \%$, especially in the eastern part of Europe. Currently, the fertilizer use remains constant. It is remarkable that the meat production only decreased to a small extent after the drop in fertilizer use. Most of the food for animal production is imported from outside of Europe.

\section{Contribution of agricultural emissions to the total emissions}

In 2002 agriculture contributed $10.1 \%$ to the total greenhouse gas emissions in $\mathrm{CO}_{2}$ equivalents in the EU-15 (EEA, 2005). The greenhouse gases emitted by agriculture are nitrous oxide and methane, both of which have a far greater global warming potential than carbon dioxide. Agriculture also consumes fossil fuels for farm operations, thus emitting carbon dioxide. Of the total agricultural

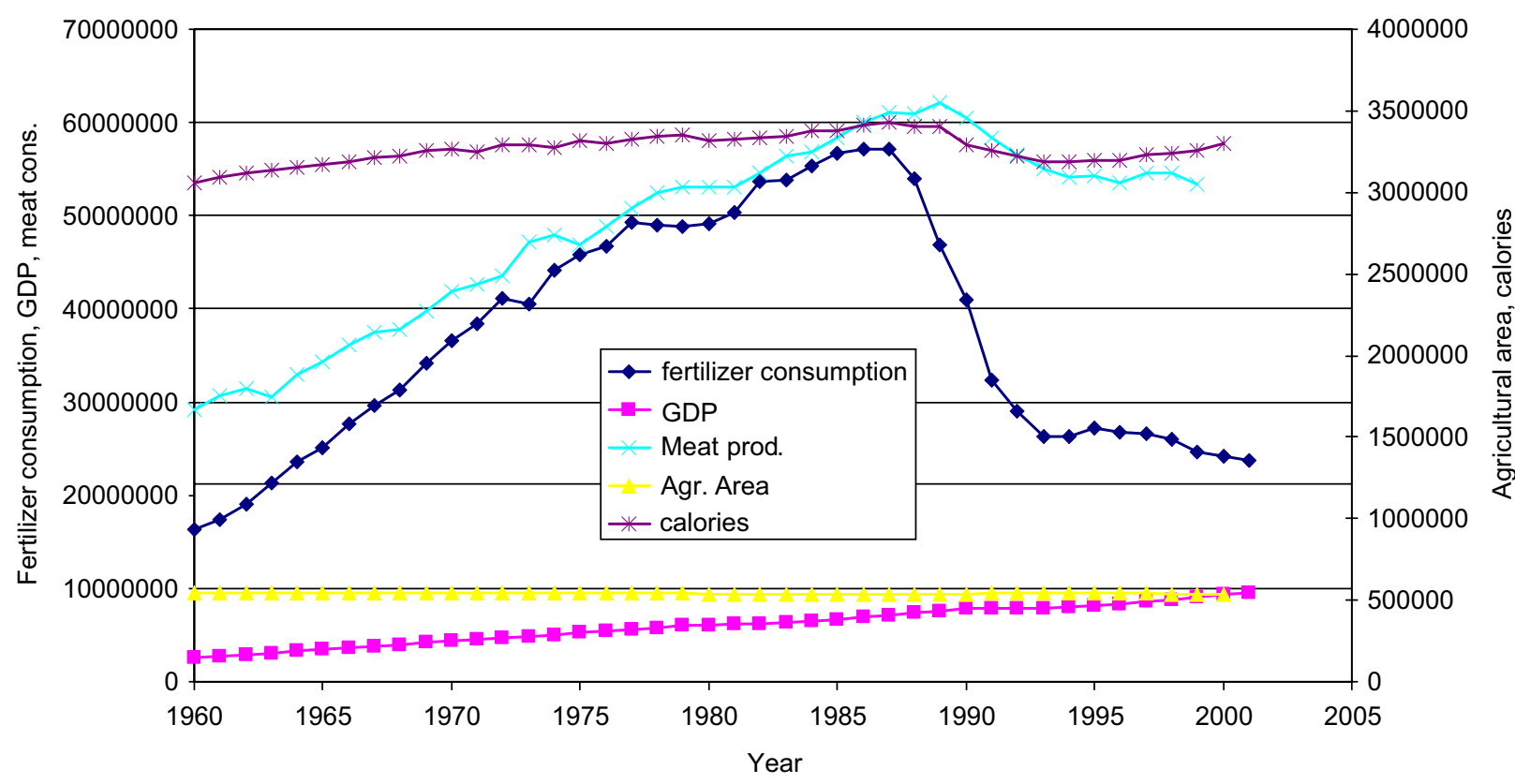

Fig. 1. Changes over time in primary drivers relevant for agricultural emissions in Europe (source: http://webdab.emep.int/scaled.html). 
contribution to the greenhouse gas emissions $\mathrm{CO}_{2}$ only comprises a small part $(0.05 \%)$ and $\mathrm{N}_{2} \mathrm{O}$ and $\mathrm{CH}_{4}$ contributed equally $4.9 \%$ (EEA, 2005). For $\mathrm{N}_{2} \mathrm{O}$ the main source is fertilizer use and for $\mathrm{CH}_{4}$ enteric fermentation of mainly cattle. The Kyoto target for the EU is 8\% reduction in 2008-2012 relative to 1990. Emissions of greenhouse gases by the agriculture sector-methane and nitrous oxide - fell by $8.7 \%$ between 1990 and 2002. This is due to a $9.4 \%$ reduction in methane from reduced livestock numbers and an $8.2 \%$ reduction in nitrous oxide from decreased nitrogenous fertilizer use and changed farm management practices. These are the emissions from known sources (e.g. stables, spreading of manure/fertilizer, etc.), but agriculture also produces indirect greenhouse gas emission, e.g. through nitrates, which are leached and run-off to surface waters and, eventually to the sea. During the transport $\mathrm{N}_{2} \mathrm{O}$ can be emitted. The same holds for the deposition of nitrogen to nature areas, which to some extent can be de-nitrified, leading to $\mathrm{N}_{2} \mathrm{O}$ emissions. Additional $\mathrm{CO}_{2}$ can be sequestered as the result of nitrogen deposition and due to agricultural practices (e.g. De Vries et al., 2006). The latter can be due to an increase of the carbon in the soil. However, when land use change, losses of carbon might be observed. The net emissions of greenhouse gases are, however, not yet quantified with some accuracy.

The contribution of agriculture to the total acidifying emissions in Western Europe is 31\% and $13 \%$ in Eastern Europe, for eutrophication the contribution is $24 \%$ and $20 \%$ for Western Europe and Eastern Europe, respectively. Fig. 2 shows the total and agricultural emission of different components in EU-15 as estimated by EMEP. The most important component is ammonia, which for more than $90 \%$ is determined by agricultural emissions. Within the EU-15, emissions of ammonia to the atmosphere from agriculture decreased by $9 \%$ between 1990 and 2002. The majority of this reduction is likely to derive from a reduction of livestock numbers across Europe (especially cattle), and the lower use of nitrogenous fertilizers across the EU-15 (Erisman et al., 2003; EEA, 2005).

The contribution of agriculture to the primary PM2.5 emissions is about 5\% and $25 \%$ for the PM10 emissions. Current investigations show that $\mathrm{PM}$ emissions from agriculture in intensive emission areas might contribute more than currently estimated. The gap between modeled and measured PM concentrations of about $50 \%$ that is currently observed might to some extent be explained by an underestimate of the agricultural sources.

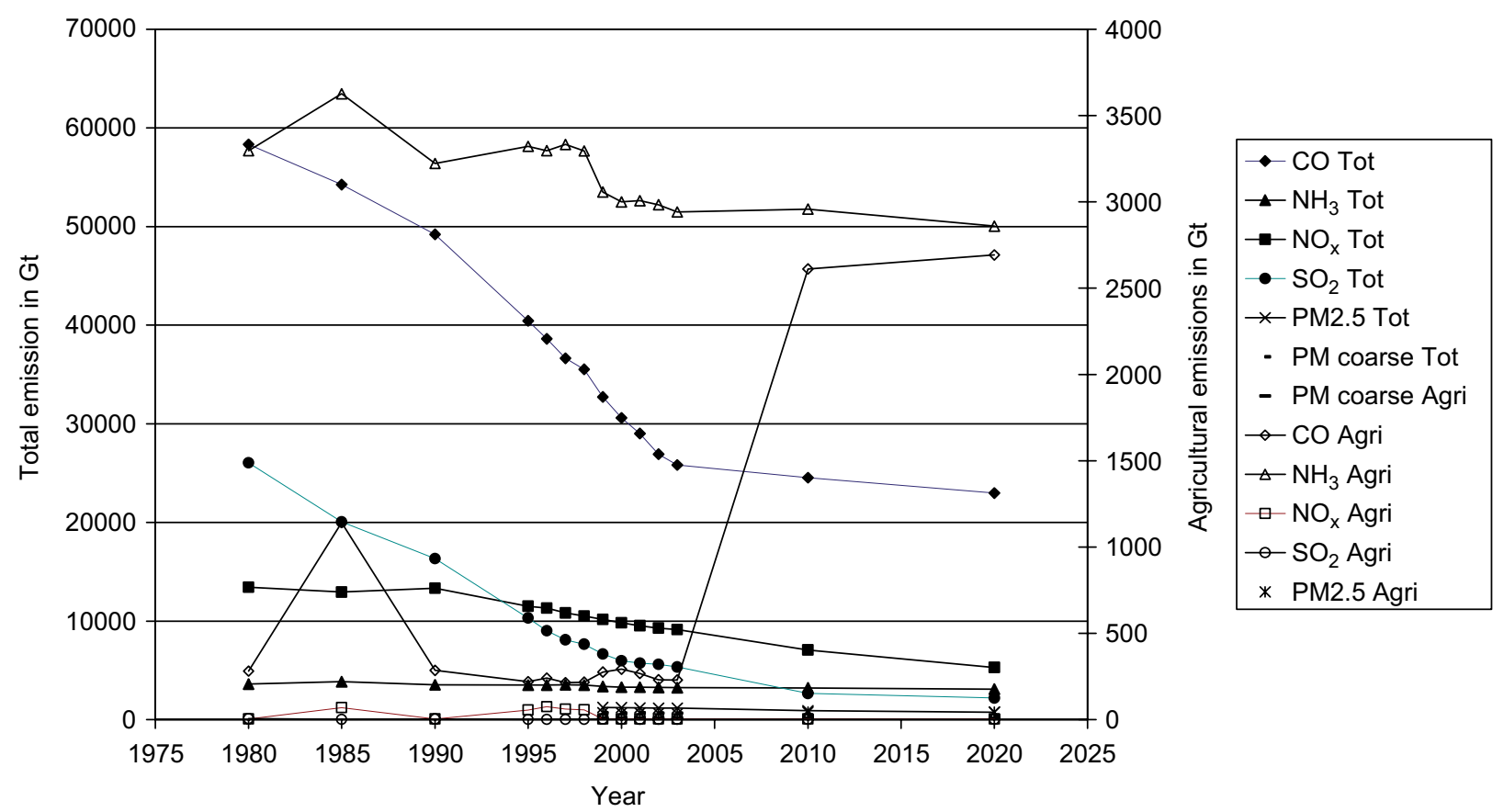

Fig. 2. Trend in best estimate emissions from all sources and from agriculture in EU-15 (Gt) (source: http://webdab.emep.int/scaled.html). 


\section{Contribution to different issues}

As shown in Fig. 2 the contribution of agriculture to the total emissions varies strongly. The highest contribution is of ammonia (90\%). Fig. 3 shows the emission-based assessment of EU-15 agriculture to different issues. The total contribution of $\mathrm{CH}_{4}$ and $\mathrm{N}_{2} \mathrm{O}$ adds up to about $10 \%$ and is significant. $\mathrm{NH}_{3}$ clearly is the most important gas to consider, contributing about $13 \%$ to particle formation, $45 \%$ to eutrophying emissions and $31 \%$ to potential acidifying emissions.

\section{Ammonia}

The change in ammonia emissions between 1990 and 2002 is shown for each country in Fig. 4. There is a big difference between the different EU-15

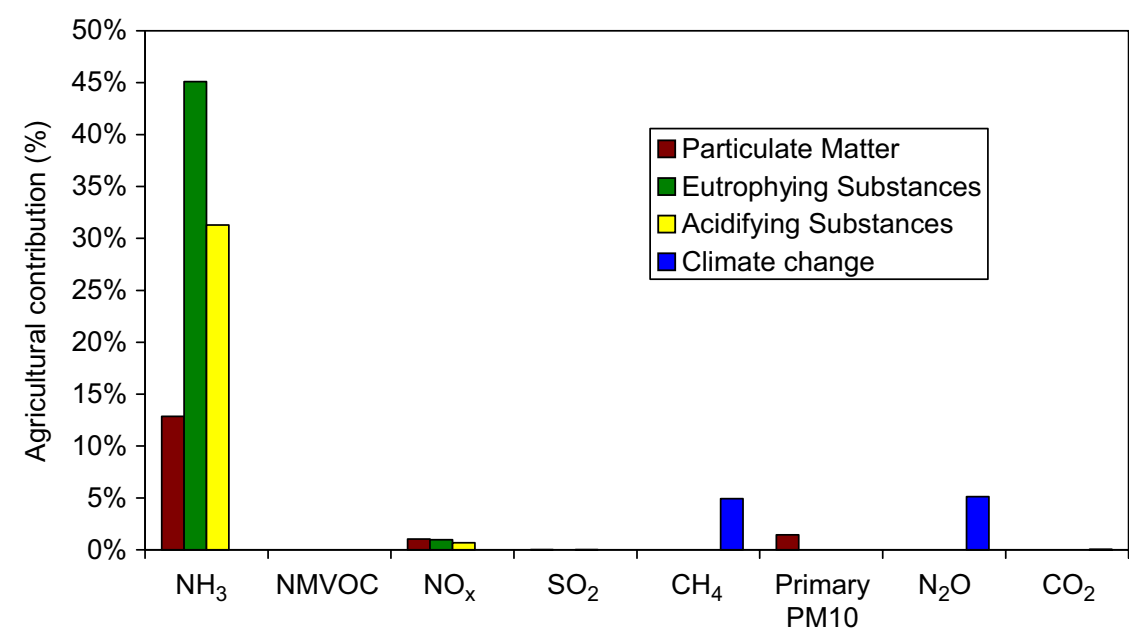

Fig. 3. Contribution of agriculture to different environmental issues.

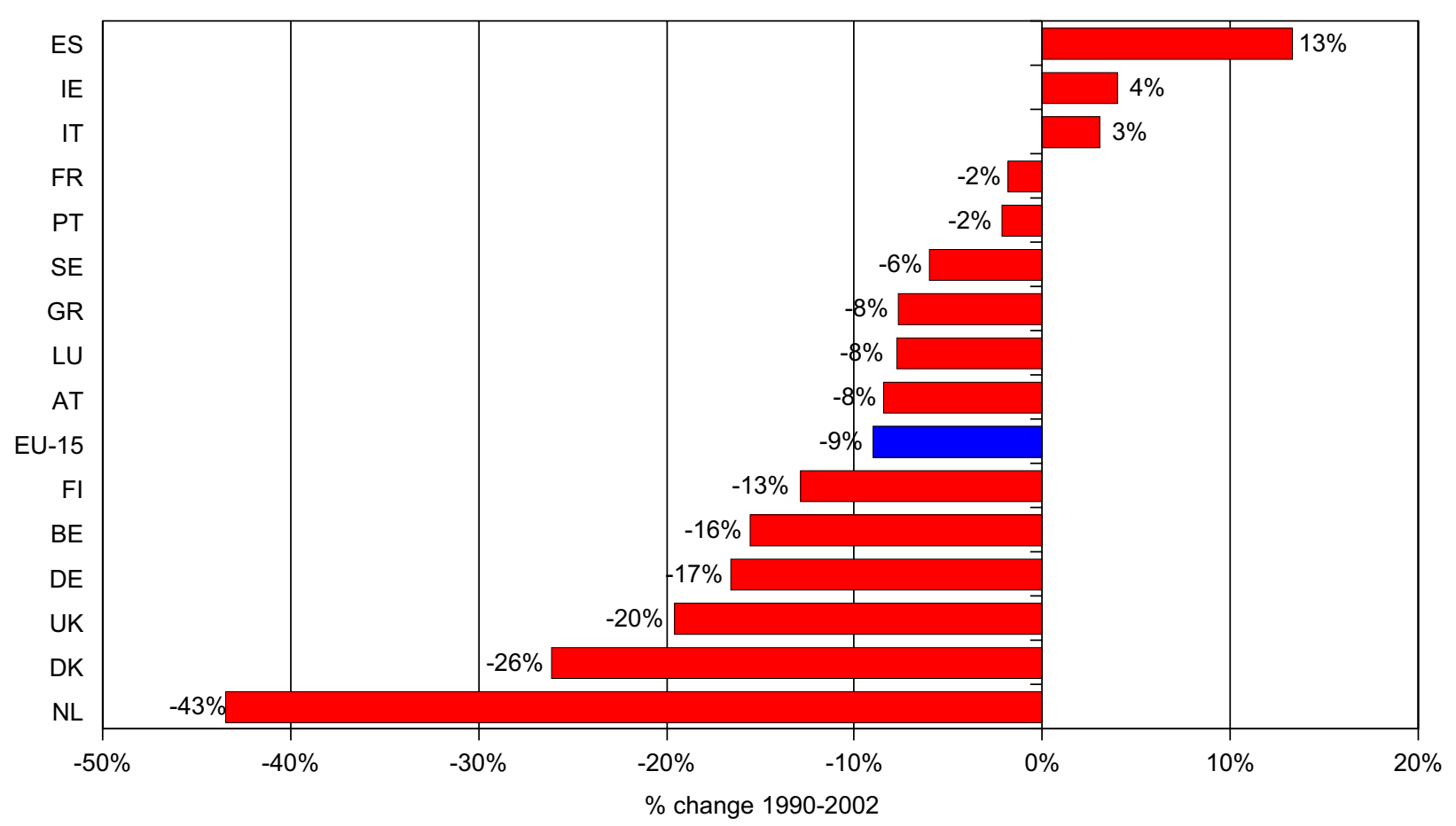

Fig. 4. Changes in ammonia emissions between 1990 and 2002 for different EU countries (EEA, 2005). 
countries, with an overall reduction of $9 \%$ for all. The most advanced reductions are found in the Netherlands, Denmark and the UK. Erisman et al. (2005) made an overview of successful and less successful policies and measures taken these past years in the Netherlands to reduce nitrogen emissions to the environment. The successful measures include: ammonia emissions were abated by the obligation to reduce the evaporation of manure and urea and as a side effect of quota that regulated the milk production. Since the introduction of the system of mineral bookkeeping in the Netherlands in 1998, there has been a significant reduction of the nitrogen surplus in the agricultural sector due to a reduction of the use of inorganic fertilizers. Less effective policies: the fact that agricultural policies for many decades have been directed exclusively towards production increase, without taking into account the environmental impacts, can be considered a policy failure. A clear example of this is the European agricultural subsidiary system, which was entirely focused on socio-economic factors, farmer's employability and supporting and increasing production, without taking the environmental consequences into account. The polluter pays principle is undermined by the exemptions and rebates for the agricultural sector and the abatement measures are not directed at the areas where they are likely to have the greatest overall effect. The EU CAP has stimulated intensification of agricultural production and contributed to environmental problems. The education program for farmers that was linked to the Dutch manure policy has reached only $20-30 \%$ of the farmers. About $50-80 \%$ of theses farmers have used the knowledge in their management. The aim of the educational program to reach all farmers was too ambitious. Manure transfer agreements that result in a better distribution of manure, do not lead to a reduction of the total amount of manure produced and of the total potential losses because it is done in an area with excess nitrogen.

The major contribution to a decrease in ammonia emissions was due to the manure injection systems (Jaarsveld, 2004), 70\% of total reduction. There still is some debate over the effectiveness of manure injection to decrease emissions and the effect of 'pollutant swapping' (increased $\mathrm{N}_{2} \mathrm{O}$ and/or $\mathrm{NO}_{3}$ emissions while reducing $\mathrm{NH}_{3}$ ). Erisman et al. (1998) showed that there was an ammonia gap, i.e. a gap between measured concentrations and those based on models with emissions as input. Currently, the models predict the changes in concentrations reasonably well (Van Jaarsveld, 2004). However, the modeled concentrations are still 25-30\% systematically lower than measured. The representativity of the measurements was checked and can therefore not be the reason for the gap. Results of an extensive measurement and assessment study in the Netherlands, the so-called 'Veld project' (Smits et al., 2005) revealed that the same gap could be observed between measurements and models. The explanation for the gap is the limited description of dry deposition, especially in agricultural areas where emissions take place and the underestimation of emissions during land application of manure by injection. The last is especially due to the machines, which are not always clean, the neatness of application and the laboratory versus the field applications (Erisman and Monteny, 1998; Smits et al., 2005; van Jaarsveld et al., 2000). This relates to the issue of spatial and temporal description of emissions, which is very difficult because of the large variation in environmental conditions, sources, management and weather conditions.

\section{Current issues in research}

In several international publications the state of knowledge on ammonia research issues is presented (e.g. Denmead et al., 1974; Aneja et al., 2001; Krupa, 2003; Anderson et al., 2003; Sutton et al., 2007). Here we focus on the European situation and research, using much of the Dutch literature. The main uncertainties in emission estimates related to the issues that cause the ammonia gap: spatial and temporal variation in emission and deposition. Weather conditions play an important role in emissions, especially for diffuse (non-point source) emissions. Wind, radiation and precipitation are important factors for volatilization and chemistry. It might affect the conversion of ammonia into ammonium through the influence on its equilibrium with ammonium in solution or soil, and the evaporation rates, because of the influence of the liquid-air equilibrium. Diffusive sources have been studied by the plume method as described in Hensen and Scharff (2001). It is a labor-intensive method but by using a tracer and a plume model, cross-wind integrated concentration profiles capture the whole emission of diffuse sources and can be used for parameterization of emission factors. In the past years wet-denuder techniques have been used to determine the cross-wind integrated concentration 
(e.g. Erisman et al., 2001). Currently, tunable diode lasers and quantum cascade lasers are being used for $\mathrm{NH}_{3}, \mathrm{~N}_{2} \mathrm{O}$ and $\mathrm{CH}_{4}$ emission measurements (Hensen et al., 2006). Methane plume measurements carried out within the Greengrass EU project (www. clermont.inra.fr/greengrass/) showed that the emission factor for dairy cows in the Netherlands was above the level used in the national methane inventory. Evaluation of this emission factor with better accurate data on animal weight and milk production has provided a new emission factor, which is $20 \%$ higher than used before.

The second main issue is the biosphere-atmosphere exchange of ammonia. After deposition $\mathrm{NH}_{3}$ can be re-emitted when the ambient concentration decreases and therewith the equilibrium shifted. Furthermore, fertilized fields can first act as an emission source, but again, when the ambient concentration increases because of nearby sources, deposition might occur. The atmosphere-biosphere exchange rate in source areas is therefore largely driven by this equilibrium. This is a highly spatial and a temporal variable process, which is now beginning to be understood on single sites where measurements of the atmosphere-biosphere exchange take place (Sutton et al., 1998; Nemitz et al., 2000; Erisman et al., 2005a). However, the challenge will be to model fluxes on the regional or landscape scale where both emission and deposition take place at the same time. Therefore, currently experiments are set up within the Integrated EU project NitroEurope that focuses on this issue.
Landscape scale experiments will be conducted in the UK, France, Denmark, Italy and The Netherlands. In The Netherlands a set of three $5 \times 5 \mathrm{~km}^{2}$ areas with contrasting management are embedded in a $60 \times 60 \mathrm{~km}^{2}$ area. In each test area $10-20$ passive sampler locations are used to obtain a spatial distribution of the $\mathrm{NH}_{3}$ concentration on a bi-weekly/monthly basis. Another 30 locations in the larger area are used to establish background conditions for the test areas. In two test areas high temporal resolution concentration monitoring for $\mathrm{NH}_{3}$ will be used, flux and plume measurements will be carried out on a campaign basis in these areas (Bleeker et al., to be published). Fig. 5 shows an example of a part of one of the $5 \times 5 \mathrm{~km}^{2}$ areas. The black dots in the graph are farm sites for which activity data (animal numbers, etc.) is available. The blue dots are three of the passive sampler locations. The curve around the passive sampler location shows from which directions significant contributions of $\mathrm{NH}_{3}$ to the receptor location can be expected based on the relative source strength of the different farms. By using this information, together with meteorological data and a dispersion model the emissions can be estimated.

The last pressing issue is the contribution of agriculture to PM concentrations, both primary PM10 emissions as well as secondary formation of PM2.5 with $\mathrm{NH}_{3}$ as precursor. Erisman and Schaap (2004) presented scenario studies for different regions in Europe, where only $\mathrm{SO}_{2}$, only $\mathrm{NO}_{x}$ or only $\mathrm{NH}_{3}$ emissions were reduced compared to

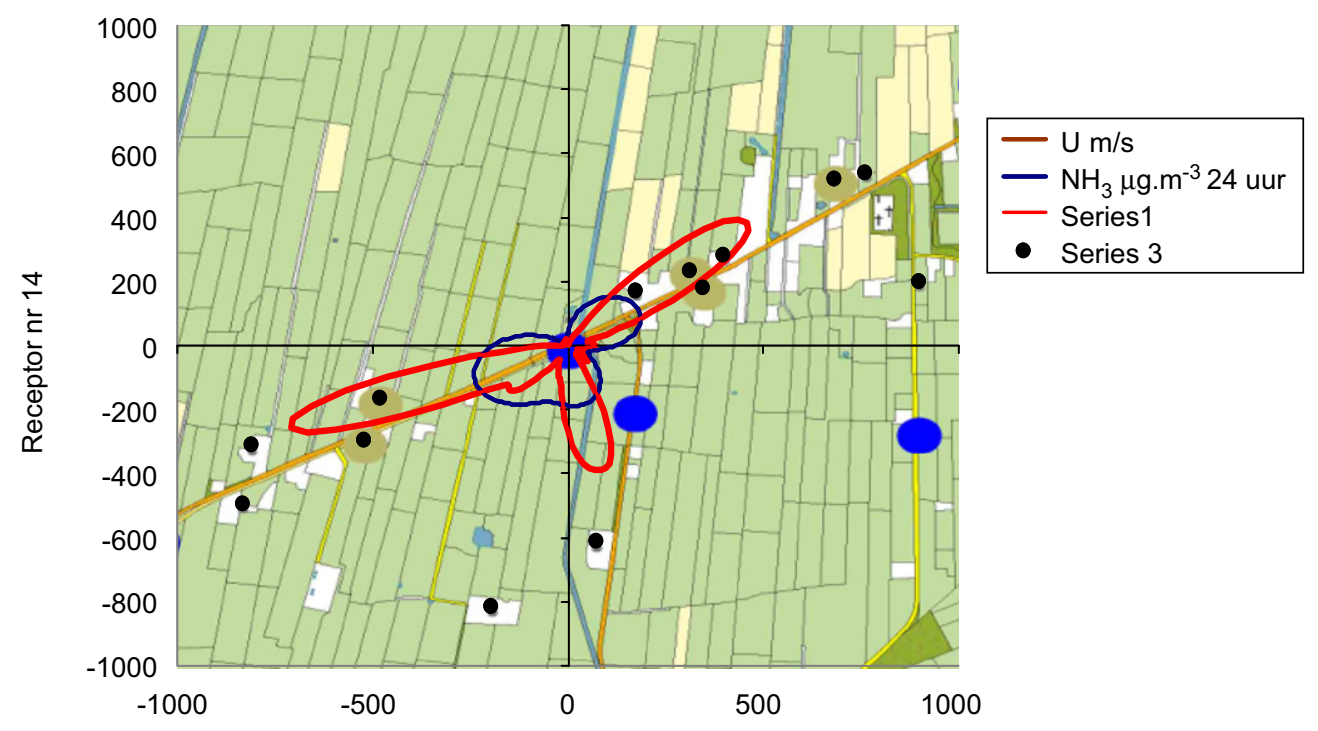

Fig. 5. Landscape scale research using passive samplers and continuous measurements in the Netherlands. 

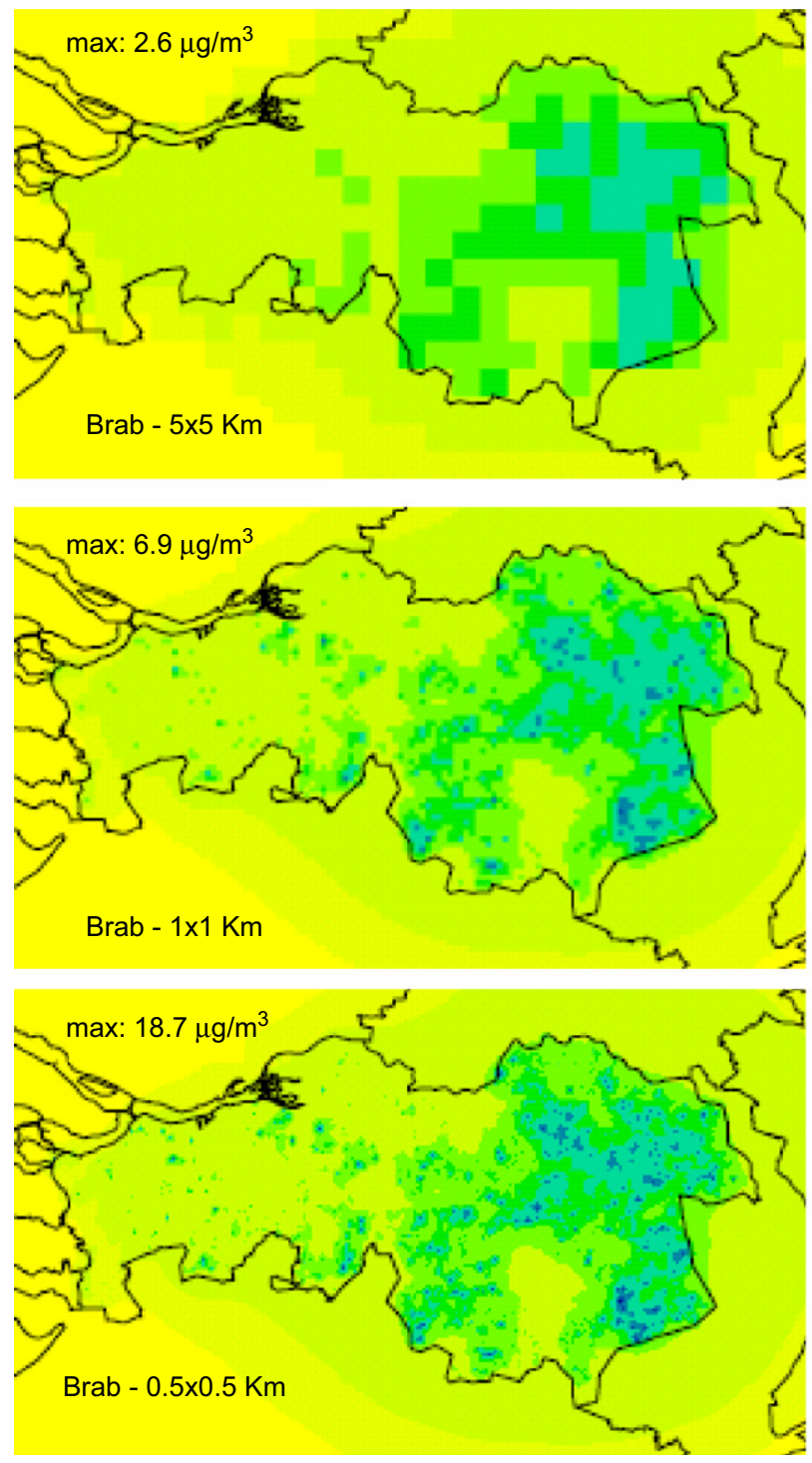

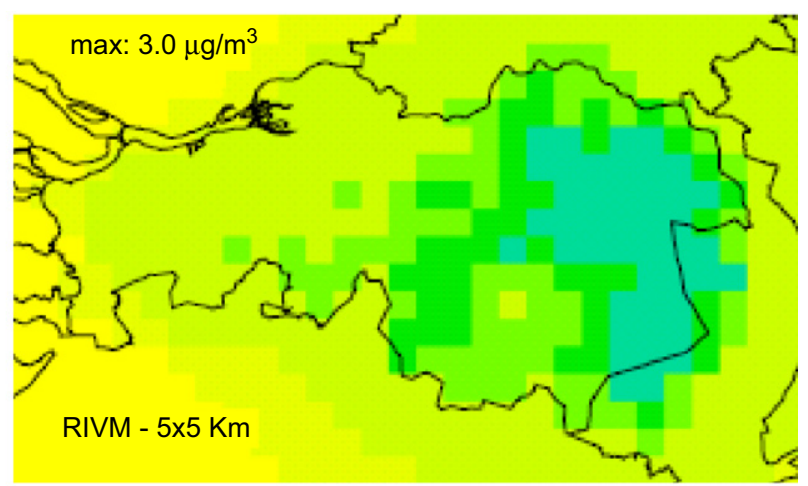

PM10 concentration $\left(\mathrm{mg} / \mathrm{m}^{3}\right)$

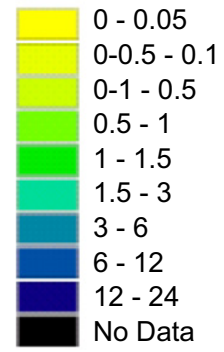

Fig. 6. Different mapping scales for PM10 concentration in North Brabant in the Netherlands and its influence on the concentration.

reducing the three together and going further with $\mathrm{NH}_{3}$ emission reduction. They concluded that PM2.5 concentrations can best be reduced when all three gas emissions are reduced, but since sulfur and $\mathrm{NO}_{x}$ is still in excess over $\mathrm{NH}_{3}$, further $\mathrm{NH}_{3}$ reductions were effective in reducing PM2.5. These scenarios show that for abating PM2.5, it is effective and necessary to reduce $\mathrm{NH}_{3}$. Current abatement for $\mathrm{NH}_{3}$ is too small to be effective.

A recent assessment of the contribution of primary PM emissions from animal housing systems shows that the local scale needs to be taken into account. If the concentrations are mapped on a large scale the contribution is limited to about $20 \%$. However, if you zoom in to $1 \times 1 \mathrm{~km}^{2}$ and even further to the area directly surrounding the farms in the Netherlands, it was shown that single farms can even lead to exceedances of the limit value for PM10 (see Fig. 6).

\section{Future predictions}

All EU-15 Member States have action plans for climate change and air quality. Most plans and programs under the national emission ceilings (NEC) directive include measures to reduce 
ammonia emissions from agriculture due to their negative health and environmental effects. According to current projections (which exclude potential effects of the 2003 CAP reform) many Member States are likely to miss their 2010 ammonia reduction target under the NEC directive. The predictions are shown in Fig. 2. The agriculture sector can make a positive contribution to reducing greenhouse gases through the production of bioenergy, thus substituting for fossil fuels. Agriculture at present contributes $3.6 \%$ of total renewable energy produced and $0.3 \%$ of total primary energy produced in the EU (EEA, 2003).

The interaction of ammonia with different environmental issues like the above-mentioned climate change and air quality, but also with acidification, eutrophication, biodiversity, etc. and the interaction with other compounds ask for an integrated approach when trying to abate the excessive ammonia emissions. This becomes even more important because the contribution of ammonia to these issues is increasing. While past policy mainly focused on single pollutants, while addressing single effects, at present a multi-pollutant/ multi-effect approach is used e.g. in the UNECE Convention on Long-Range Transboundary Air Pollution and the EU National Emission Ceiling Directive. Within such an approach abatement measures are developed, taking into account the interactions and feedback mechanisms between the different compounds and their effects. Ammonia should receive much more attention in these protocols.

The CAP has been one of the important drivers of farm intensification and specialization in the EU. Market pressures and technological development have also contributed to these trends, which are very strong in some sectors that do not benefit from public support (e.g. pigs, poultry, potatoes). Intensive farming has had significant impacts on the environment. Public concerns related to production methods and some reorientation of the CAP has created new opportunities, for example through labeling and agri-environment schemes, for farmers to reduce pressures on the environment. Agriculture in the central and Eastern Europe countries is likely to intensify when they have full access to the CAP although there is an evolving agri-environmental policy framework and some opportunities under the special accession program for agriculture and rural development to address this risk. The CAP will apply to new Member States in a modified form, which may reduce incentives for increasing production. The transition of the CAP towards the decoupling of the payments from productivity and the linkage of single farm payments to the compliance with environmental legislation ("cross-compliance") are important drivers for the environmental impact of agriculture.

Erisman et al. (2005) made an overview of the effectiveness of policies in the Netherlands and Europe to reduce nitrogen emissions. The main conclusion is that policies should not be focused on increasing production alone, rather than including the farm nutrient efficiencies. Through the focus on production, combined with the low cost of e.g. concentrates (animal feed) and fertilizers, the efficiency of nutrient cycling at the farms has been neglected. Measures include taxes or financial grants, and the targets setting for $\mathrm{N}$ losses. Furthermore, the closing of cycles should be done at different scales at the same time. We are accustomed to seek our improvements in technological options. There are potential technologies that might lead to substantial emission reduction (nitrification inhibitors, fermentation of manure, etc.). These are important, but the reduction in environmental load they cause should not lead to increased import of raw materials, leading to changes in cycles at supranational scales. Furthermore, other components (such as carbon) and issues (access to freshwater) should be taken into account to prevent trade-offs. If financial incentives are given it is important to secure the period that these incentives will last, in order to guarantee a return of investment.

\section{Concluding remarks}

The largest uncertainty in emission estimates is due to the difficulties to quantify diffuse or nonpoint sources and the generalization of the different sources, varying in space and time. New methods are developed to measure accurately and with enough temporal resolution the ambient concentrations. This is necessary to improve the quantification of individual sources, and the regional sources. The landscape scale is so far not well quantified. Major uncertainties rest in the local and regional ammonia emissions and its temporal variation and in the PM emissions from agricultural sources. Within the multi-pollutant, multi-effect approach ammonia abatement has been identified as important and the first agreements for reductions are 
made. However, in order to meet targets on acidification, eutrophication and PM concentrations, much larger reductions should be aimed at. Policies to reduce ammonia emissions should take the cascade of nitrogen into account. This means that they should be directed to decreasing the production of reactive nitrogen from $\mathrm{N}_{2}$, or to increasing the conversion of reactive nitrogen e.g. by de-nitrification back into $\mathrm{N}_{2}$.

\section{References}

Anderson, N., Strader, R., Davidson, C., 2003. Airborne reduced nitrogen: ammonia emissions from agriculture and other sources. Environment International 29, 277-286.

Aneja, V.P., Roelle, P.A., Murray, G.C., Southerland, J., Erisman, J.W., 2001. Atmospheric nitrogen compounds II: emissions, transport, transformation, deposition and assessment. Atmospheric Environment 35, 1903-1911.

Bleeker, A., Hensen, A., Gies, E., De Vries, W., Kros, J., Sonneveld, M.P.W., 2007. Multi-purpose ammonia measurements on a landscape level, to be published.

De Vries, W., Butterbach Bahl, K., Denier van der Gon, H., Oenema, O., 2006. The impact of atmospheric nitrogen deposition on the exchange of carbon dioxide, nitrous oxide and methane from European forests. Global Change Biology $12,1151-1173$.

Denmead, O.T., Simpson, J.R., Freney, J.R., 1974. Ammonia flux into the atmosphere from a grazed pasture. Science 185 , 609-610.

EEA, 2003. Europe's Environment: The Third Assessment. EEA, Copenhagen, pp. 324, ISBN 92-9167-574-1.

EEA, 2005. Agriculture and environment in EU-15. The IRENA Indicator Report, EEA, Copenhagen, p. 128, ISBN 92-9167$779-5$.

Erisman, J.W., Monteny, G.J., 1998. Consequences of new scientific findings for future abatement of ammonia emissions. Environmental Pollution 102, 275-282.

Erisman, J.W., Schaap, M., 2004. The need for ammonia abatement with respect to secondary PM reductions in Europe. Environmental Pollution 129, 159-163.

Erisman, J.W., Bleeker, A., van Jaarsveld, J.A., 1998. Evaluation of ammonia emission abatement on the basis of measurements and model calculations. Environmental Pollution 102, 269-274.

Erisman, J.W., Otjes, R., Hensen, A., Jongejan, P., van den Bulk, P., Khlystov, A., Slanina, J., 2001. Instrument development and application in studies and monitoring of ambient ammonia. Atmospheric Environment 35, 1913-1922.

Erisman, J.W., Grennfelt, P., Sutton, M., 2003. The European perspective on nitrogen emission and deposition. Environment International 29, 311-325.
Erisman, J.W., Nelleke, Domburg, Wim de, Vries, Hans, Kros, Bronno de, Haan, Kaj, Sanders, 2005. The Dutch N-cascade in the European perspective. Science in China 48, 827-842.

Erisman, J.W., Hensen, A., Mosquera, J., Sutton, M., Fowler, D., 2005. Deposition monitoring networks: what monitoring is required to give reasonable estimates of ammonia/ammonium? Environmental Pollution 135, 419-431.

Hensen, A., Scharff, H., 2001. Methane emission estimates from landfills obtained with dynamic plume measurements. Water, Air and Soil Pollution 1, 455-464.

Hensen, A., Groot, T.T., Van den Bulk, W.C.M., Vermeulen, A.T., Olesen, J.E., Schelde, K., 2006. Dairy farm $\mathrm{CH}_{4}$ and $\mathrm{N}_{2} \mathrm{O}$ emissions from one square meter to the full farm scale. Agriculture Ecosystems and Environment 112, $146-152$.

Krupa, S.V., Effects of atmospheric ammonia $\left(\mathrm{NH}_{3}\right)$ on terrestrial vegetation: a review. Environmental Pollution 124, 179-221.

Nemitz, E., Sutton, M.A., Schjoerring, J.K., Husted, S., Wyers, G.P., 2000. Resistance modelling of ammonia exchange over oilseed rape. Agricultural and Forest Meteorology 105, 405-425.

Smits, M.C.J., Jaarsveld JA, van., Mokveld, L.J., Vellinga, O., Stolk, A., Hoek, K.W., van der, Pul WAJ van 2005. VELDproject: a detailed inventarisation of ammonia emissions and concentrations in an agricultural area. RIVM rapport 500033002; A\&F Report 429, A\&F, Wageningen, the Netherlands, ISBN: 9067549193, 183p (in Dutch).

Sutton, M., Nemitz, E., Erisman, J.W., Beier, C., ButterbachBahl, K., Pierre, C., de Vries, W., Cotrufo, F., Skiba, U., di Marco, C., Jones, S., Soussana, J.-F., Loubet, B., Twigg, M., Whitehead, J., Gallagher, M., Neftel, A., Flechard, C., Herrmann, B., Calanca, P., Schjoerring, J., Daemmgen, U., Horvath, L., Tang, L., Emmett, B., Tietema, A., Penuelas, J., Kesik, M., Brueggemann, N., Pilegaard, K., Vesala, T., Campbell, C., Olesen, J., Theobald, M., Levy, P., Mobbs, D., Milne, R., Viovy, N., Vuichard, N., Smith, J., Smith, P., Bergamaschi, P., Fowler, D., Reis, S., 2007. Challenges in quantifying biosphere-atmosphere exchange of nitrogen species. Environmental Pollution, in press.

Sutton, M.A., Burkhardt, J.K., Guerin, D., Nemitz, E., Fowler, D., 1998. Development of resistance models to describe measurements of bi-directional ammonia surface atmosphere exchange. Atmospheric Environment 32 (3), 473-480.

Van Jaarsveld, J.A., Bleeker, A., Hoogervorst, N.J.P., 2000. Evaluation ammonia reduction by means of measurements and model calculations. RIVM Report No. 722108025, National Institute of Public Health and Environment, The Netherlands (in Dutch).

Van Jaarsveld, J.A., 2004. The operational priority substances model: description and validation of OPS-pro 4.1. RIVM Report No. 500045001/2004, National Institute of Public Health and Environment, The Netherlands. 